\title{
OPINIÃO PÚBLICA, ELEIÇÕES E PARTICIPAÇÃO POLÍTICA NAS DEMOCRACIAS CONTEMPORÂNEAS
}

O dossiê "Opinião pública, eleições e participação política nas democracias contemporâneas" reúne artigos que possibilitam avançar no entendimento da formação da opinião pública e seus impactos sobre o funcionamento da democracia em sua dimensão institucional, suas regras e seus procedimentos. O processo eleitoral é analisado em grande parte dos artigos e transpõem as fronteiras nacionais ao incorporar outras realidades da região ibero-americana, como Argentina, Uruguai e Portugal. Estes países, a despeito de possuírem pontos de identidade com o Brasil, distinguem-se por seus diferentes arranjos institucionais, conduta política dos cidadãos e consumo de informações. A introdução de outras regiões possibilita a comparação e permite avançar na interpretação das diferenças e similitude políticas entre estas realidades.

Os artigos articulam outros aspectos mais subjetivos e normativos presentes na democracia e na opinião pública, que podem orientar os partidos e as condutas políticas, como por exemplo a ideologia. A ideologia pode ser encontrada tanto nos programas partidários, quanto nas informações que são consumidas pelos cidadãos. Mas, para além da seleção de fontes de informação mais tradicionais, como a imprensa escrita e a televisão, a sociedade se vê diante de novos fluxos comunicacionais, que produzem mobilização social e política: as redes sociais. O uso de novas tecnologias nas campanhas políticas permite que elites e cidadãos interajam de modo mais ágil, modificando as formas tradicionais de persuasão e produzindo campanhas eleitorais de novo tipo, fenômeno ainda pouco estudado pela literatura.

Para analisar os temas vinculados à opinião pública - eleições, redes sociais, ideologias e conduta política - foram introduzidas teorias que incorporam aportes de diferentes áreas das ciências sociais e humanas política, comunicação, psicologia, sociologia -, demonstrando que a interdisciplinaridade é o caminho mais adequado para a apreensão dos fenômenos mais recentes ocorridos nas democracias contemporâneas. Como resultado da diversidade teórica nos pontos de partida, as metodologias igualmente se sustentam em originais fontes de dados, como surveys, análises de conteúdos, dados eleitorais agregados, informações coletadas na Internet e entrevistas qualitativas.

Este dossiê é aberto com um bloco de ensaios cujo foco é a ideologia, em suas variadas concepções. Os artigos tratam de interpretá-la no consumo das informações produzidas pelos meios de comunicação, na cidade de Córdoba (Argentina); nos programas partidários portugueses ou, ainda, discutindo a ideologia no comportamento político dos brasileiros.

Apesar de estar pouco presente nos mais recentes estudos produzidos no Brasil, a ideologia foi tema bastante discutido na literatura internacional, 
sobretudo após a II Guerra Mundial. Entretanto, a sua concepção não é consensual e propriedades distintas são atribuídas ao termo. Ideologia pode ser definida a partir de abordagens teleológicas, através de suas funções e mesmo por seus efeitos. Assim, é concebida como um conjunto de valores compartilhados por um grupo, como promotora da estabilidade do sistema político e como ideias coerentes que formam um corpo consistente. Ela ainda é abordada pela literatura como crença e compromisso com um pensamento voltado para a mudança do status quo.

O consumo de informações veiculadas nos meios de comunicação em sua conexão com a ideologia é tema ainda pouco tratado na literatura da ciência política nacional. Valendo-se de uma reflexão em que são aportadas teorias da psicologia política, o artigo Ideología Política y Prácticas Mediatizadas de Consumo Informativo, produzido por Silvina Brussino et. al., pesquisadores da Universidad de Córdoba, analisa o consumo midiático e a ideologia, tendo como base empírica um survey realizado na cidade argentina de Córdoba.

O cerne teórico do texto é o de que, por seu caráter heurístico, a ideologia permite a interpretação dos fenômenos sociais e políticos, pois os cidadãos a utilizam para simplificar o seu universo político, ao mesmo tempo em que ela constitui as relações sociais e os contextos de interação entre os indivíduos. Neste sentido, os autores buscam compreender as instâncias e lógicas da produção, bem como dos contextos de recepção e de apropriação das informações pelos cidadãos. A partir da teoria do "consumo seletivo", no qual a ideologia e as características demográficas, que marcam as diferenças entre os grupos sociais, devem estar associadas às preferências pela recepção de determinadas informações, examina-se o consumo midiático de informação política. A ideologia é mensurada através da escala de auto-posicionamento esquerda-direita. Ao criar índices e realizar testes estatísticos, os autores encontram achados originais, que permitem avançar na compreensão dos nexos entre valores, ideologia política e consumo de informações.

Ideology in the campaign programmes of Portuguese political parties: the 2009 European elections, artigo de Paula do Espírito Santo, da Universidade Técnica de Lisboa, examina a presença da ideologia nos programas dos principais partidos portugueses que disputaram as eleições para o parlamento europeu em 2009. Os programas políticos que estes partidos ofereceram para concorrer às eleições europeias diferiam bastante entre si, tanto de forma geral, quanto em relação ao número de páginas e ao conteúdo das imagens. A autora utiliza no exame a técnica de "análise de conteúdo" e, para tanto, cria categorias, entre as quais a ideologia, que é central em seu estudo. Além da ideologia, são inseridas outras categorias para classificar os enunciados dos programas partidários, tais como valores sociopolíticos e valores políticos.

Espírito Santo argumenta que esta diferenciação é importante, pois, enquanto o conceito de ideologia inclui posições doutrinárias que distinguem os partidos, como direita, esquerda, socialismo, conservadorismo, liberalismo, 
os valores sociopolíticos abarcam ideias sem conotação ideológica direta, tais como juventude, confiança e solidariedade. Já os valores políticos são expressões vinculadas a uma determinada visão sobre o nacional e a função do Estado (igualdade, nacionalismo, coesão nacional, estabilidade, democracia, entre outros). A hipótese da autora é a de que as mensagens ideológicas e os valores sociopolíticos e políticos são distribuídos de maneira desigual entre os programas partidários que nortearam as eleições europeias em Portugal. Assim, apesar da ideologia ser uma categoria importante e estar presente em alguns dos programas analisados, ela não foi capaz de gerar adesão eleitoral e promover a vitória dos partidos mais ideológicos.

As eleições brasileiras distinguem-se das portuguesas em diversos aspectos, seja pelo pouco enraizamento dos partidos políticos, seja porque as legislações são distintas. O comportamento eleitoral, especialmente na cidade de Salvador, é o objeto de Janaína do Nascimento, pesquisadora do JN Pesquisa e Consultoria. Em Comportamento Eleitoral: racionalidade, identidade e personalismo no voto em Lula da Silva em Salvador, são apresentados os principais argumentos que a literatura nacional utiliza para explicar a conduta do eleitor e sua decisão de voto, nas eleições presidenciais de 2006, cujo resultado foi a reeleição de Luiz Inácio Lula da Silva (PT).

Com base em inúmeros grupos focais realizados na capital baiana, a hipótese do artigo é a de que se o padrão do voto em Lula da Silva não foi totalmente ideológico, também não pode ser classificado como intuitivo, irracional e emocional. Para além das teorias sobre a conduta personalista do eleitor, Nascimento sustenta que o Presidente foi reeleito em função de uma conjunção de fatores que agregam decisões racionais e retrospectivas. Mas, como o fenômeno do voto é multicausal, tais explicações são insuficientes para interpretar os resultados das eleições presidenciais de 2006. A autora acrescenta às suas análises elementos subjetivos extraídos das teorias identitárias, nas quais a categoria "reconhecimento" é de extrema relevância. Por isso, a identidade - a "nordestinidade" - teve efeitos sobre a conduta política do eleitor em Salvador.

As eleições presidenciais no Uruguai também são objeto de análise em dois artigos que integram este dossiê. Em Participación Electoral en las Elecciones Primarias en Uruguay, Daniel Buquet e Rafael Piñeiro, ambos da Universidad de la República, se dedicam a investigar as eleições primárias para a seleção dos candidatos presidenciais e identificar quais os principais elementos que motivam a participação eleitoral no referido processo. Outro objetivo dos autores é verificar os efeitos de tal participação no perfil dos candidatos que tendem a ser eleitos.

Além de propiciar um panorama interessante e atual sobre o processo de seleção de candidatos presidenciais no Uruguai, Buquet e Piñeiro demonstram ainda como variáveis ideológicas e sociodemográficas influem na participação eleitoral e sua relação com a preferência partidária dos eleitores. Um dos aspectos que torna o estudo ainda mais interessante é que o Uruguai é o único país onde eleições simultâneas e abertas para a seleção dos 
candidatos presidenciais são obrigatórias.

Ainda sobre o comportamento político no Uruguai, temos o artigo Las Claves del Éxito de Mujica en las Elecciones Presidenciales Uruguayas de 2009, de José Raúl Rodríguez e Daniela Vairo, respectivamente da Opción Consultores e do Instituto de Estudos Sociais e Políticos da Universidade Estadual do Rio de Janeiro, que tem como objetivo apresentar as razões da vitória de José Mujica nas eleições presidenciais daquele país em 2009. Os autores concluem que as políticas implementadas na gestão anterior, a boa avaliação do governo e uma campanha eleitoral bem conduzida são os elementos chave para a compreensão da reeleição da Frente Ampla e de seu candidato José Mujica. Ao lado de seu propósito central, Rodríguez e Vairo traçam um perfil da evolução recente, a partir dos anos setenta, do sistema partidário uruguaio, bem como dos padrões de competição e a avaliação dos partidos pela opinião pública. Dessa forma, o artigo permite uma compreensão mais ampla da política uruguaia nos anos recentes.

O bloco final do dossiê trata da relação entre eleições para cargos majoritários e a mídia, especialmente para prefeito e senador. No artigo Uso da Internet e Oportunidades de Participação Política Virtual nas Eleições Municipais de Outubro de 2008 no Brasil, Sérgio Braga, Maria Alejandra Nicolás e Andressa Silvério França, todos da Universidade Federal do Paraná, analisam o papel da Internet nas disputas eleitorais. Os autores investigam, principalmente, como essa nova mídia foi utilizada pelos políticos como mecanismo de maximização de votos.

Os dados apresentados mostram que, ao menos em 2008, encontrouse um cenário de "digital divide" no Brasil. Os candidatos a prefeito dos grandes partidos, da esquerda e direta, e das regiões mais prósperas, foram os que mais investiram na Internet como forma de ampliar o seu apoio eleitoral. Ainda que o foco do artigo tenha sido as eleições municipais de 2008, esses e outros achados oferecem importantes insights para análises de pleitos posteriores, quando poder-se-á comparar se candidatos de partidos menores, e das regiões menos prósperas, disponibilizaram mais recursos para as novas mídias em suas campanhas, e se houve uma ampliação do uso dos chamadas "redes sociais" pelos políticos.

No Brasil, ainda são poucos os trabalhos sobre comportamento eleitoral que buscam analisar, de maneira conjunta, as disputas a cargos majoritários e proporcionais. Esse é um dos méritos do trabalho $A$ Derrota de Tasso Jereissati na Disputa para o Senado em 2010: como entender a dissolução de suas bases eleitorais?, de Rejane Vasconcelos Carvalho e Jakson Alves de Aquino, ambos da Universidade Federal do Ceará, cujo objetivo é explicar as razões da perda de hegemonia do ex-senador Tasso Jereissati no estado do Ceará. Os dados apresentados no artigo não apenas sugerem a existência de um "voto casado" entre candidatos percebidos como estando no mesmo lado político (situação e oposição), como também trazem para a superfície questões importantes sobre a influência das elites políticas e os efeitos das campanhas eleitorais no processo de decisão do voto dos 
eleitores.

Ainda nesta edição da Revista Debates, são apresentados dois textos na seção de Artigos livres e um nas Notas de Pesquisa.

Em Artigos, o texto Modelos de acompanhamento jornalístico da Política em Portugal, de autoria de Renato Ferreira e Ricardo Jorge Pinto, ambos da Universidade Fernando Pessoa (Portugal), traz uma análise do jornalismo político em Portugal. A pesquisa tem como base de análise três jornais portugueses, sendo que as notícias avaliadas são datadas dos dias de campanha das eleições presidenciais do presente ano de 2011. A partir de cinco categorias de análise, nas quais são classificadas as notícias das campanhas eleitorais de candidatos à presidência, os autores testam a hipótese de que o jornalismo político de Portugal é horizontal. Os autores buscam um modelo explicativo da forma como a política é acompanhada pelos media.

O segundo texto desta seção, Posiciones Políticas vs Mercado Electoral, é de autoria de Octaviano Moya Delgado, da Universidad Autonoma de Sinaloa (México). A hipótese que busca comprovar é a de que os eleitores decidem seu voto pensando, antes da ideologia, em benefícios que os candidatos podem oferecer caso vençam o pleito. Para testar sua hipótese o autor analisou as dimensiones empíricas de: contexto e atores na eleição (eleitores, candidatos e partidos), as posições político-ideológicas, os benefícios esperados (avaliações de governos e previsões) e as chamadas condições de competição (elementos relevantes para a modificação do voto). A pesquisa, de painel, ocorreu em Mazatlán (Sinaloa - México), município definido como de alta competitividade eleitoral.

Esta edição da Revista Debates é finalizada com as Notas de Pesquisa de Denise Paiva, Milton de Souza Mendonça Sobrinho e Mariana Gabriel Sara, da Universidade Federal de Goiás. Intitulada Participação e Representação Feminina na Política em Goiás, os autores apresentam os resultados de pesquisa no estado de Goiás, em levantamento de quase trinta anos, sobre a representação feminina na política estadual. O texto alerta para a subrepresentação das mulheres na política que, como bem apontam os autores, não ocorre apenas nesta Unidade da Federação.

Esperamos, enfim, que os artigos aqui apresentados instiguem 0 debate e rendam novos estudos e pesquisas. Desejamos ao leitor uma boa leitura!

\author{
Denise Paiva ${ }^{1}$ \\ Helcimara de Souza Telles ${ }^{2}$ \\ Pedro Santos Mundim ${ }^{1}$ \\ -Organizadores do Dossiê-
}

\footnotetext{
${ }^{1}$ Faculdade de Ciências Sociais, Universidade Federal de Goiás.

2 Departamento de Ciência Política, Universidade Federal de Minas Gerais.
} 